\title{
PLANEJAMENTO INSTITUCIONAL capacidade de conduzir ações
}

Maria Josefa Del Carmen Martinez Soto

\begin{abstract}
Resumo: O texto aborda a demanda cotidiana por planejamento no ambiente de trabalho, a necessidade de desenvolver diretrizes de desenvolvimento institucional e a eficiência na produção e gestão. Associam-se, ao desempenho da atividade de planejar, a capacidade de coordenação, a persistência e a motivação. Palavras-chave: desenvolvimento institucional; coordenação; gestão.

Abstract: This text addresses the daily need for planning in the workplace, developing institutional guidelines and obtaining efficiency in production and management. Associated with the activity of planning is the capacity to coordinate, and the qualities of persistence and motivation.

Key words: institutional development; coordination; management.
\end{abstract}

Em suma, a consciência tem de estar presente para que os sentimentos influenciem o individuo que os tem, além do aqui e agora imediato

Damásio (2000)

\begin{abstract}
Os planejadores têm que sair para o mundo. Uma vez lá fora, eles precisam olhar para a sua empresa e se perguntar: que relevância essas forças externas que vemos podem ter para o mundo mais limitado de nossa própria empresa?
\end{abstract}

Geus (1998)

A necessidade de planejar - mesmo vagamente declarada como "precisamos nos organizar para"pressupõe objetivos e demanda por coordenação. Uma instituição se transforma em uma organização na medida em que é capaz de perceber e organizar a experiência e as expectativas sobre o futuro, integrando cotidianamente o conhecimento, o conteúdo da comunicação, selecionando questões e inserindo ações em torno de objetivos precisos que orientem as competências, os processos de produção, as relações e as parcerias. A falta de clareza alimenta uma cultura desordenada de enunciados sobre demandas e insatisfações à espera de atenção. Nas insti- tuições, a ação cotidiana pode não refletir as expectativas de evolução; em organizações maduras, idéias de desenvolvimento estão refletidas em suas ações. A existência de um corpo visível de políticas e de um plano viável de médio prazo, resultado de muitas interações e avaliações, pode ser o instrumento capaz de efetivamente promover esta identidade.

É necessário precisar os objetivos, perguntar pelo seu significado dentro da instituição, como é entendido, como é gerado, em que tempo é possível obter resultados, qual o impacto esperado e custo de adiar, quais as dificuldades esperadas e a experiência exigida. Este trabalho de explicitar e explicar os problemas reorganiza o entendimento das questões, integra os diversos pontos de vista, traduz as tendências em planos de ação concretos e potencializa a experiência prática e as oportunidades de melhoria.

\section{PLANO DE TRABALHO E CONSCIÊNCIA ORGANIZACIONAL}

O grau de atenção à percepção e organização de novas idéias, à qualidade dos resultados e aos fatos do ambiente 
interno e externo, que desafiam a forma como estamos atuando e exigem adaptações e ajuste de diretivas, revela a disposição em planejar e ser propositivo na experiência. É objetivo do planejamento conhecer o grau de complexidade das situações, identificando, por vezes, o "estresse" que o adiamento dos problemas já causou, configurar uma organização de equipes capazes de reconhecer os desafios e torná-los seus, desenvolver espaços de aprendizado e propostas adequadas e estabelecer realizações no tempo e representá-las em um projeto para a organização.

O plano de trabalho pode ser entendido como a "consciência organizacional atualizada e disseminada" sobre importâncias, objetivos, metas, recursos, resultados e prazos que orientam a gestão e norteiam a composição e a harmonização da agenda interna e externa.

A construção desta consciência resulta do esforço contínuo em relacionar a multiplicidade de problemas singulares que se apresentam, eleger prioridades, comunicar e explicar as necessidades e tendências do ambiente de produção e da demanda, atribuir responsabilidades e negociar compromissos dentro de uma visão de desenvolvimento. Este ideal do planejamento, muitas vezes, é alcançado no âmbito de algumas funções da gestão ou da produção e decorre da atenção que gerentes e funcionários atribuem à captação, integração e avaliação da experiência local, desenvolvendo ilhas de excelência. São sucessos pontuais, dependentes de empenhos personalizados e de lutas diárias no sentido de comprometer os recursos institucionais com produtos e prazos.

A qualidade do planejamento, entretanto, não se desenvolve da soma de planos pontuais e isolados bem-sucedidos, mas se evidencia no grau de responsabilidade e coordenação constante com que a organização seleciona, atribui e monitora um conjunto integrado de realizações. A determinação de objetivos estratégicos, operacionais e de coordenação é essencial, porém, insuficiente, sendo necessário ainda, o interesse dos funcionários e da direção, a motivação em persistir e ter presente um saudável sentido de urgência. A motivação para o planejamento tem origem no real reconhecimento das situações insatisfatórias que envolvem insegurança e incerteza e para as quais é necessário somar esforços e coordenar impaciências, em face do impacto no futuro da instituição. A motivação também pode vir da convicção de que é possível encontrar, pela reflexão e pela arte de atuar em conjunto, uma visão satisfatória e responsável, passível de ser traduzida em ações. O sistema de planejamento em uma organização pode ser avaliado pelo nível de coordenação e foco das agendas - estratégica, gerencial e operacional -, pela agilidade e acuidade com que se antecipam desafios e inovações necessárias, pela capacidade de dimensionar, captar e garantir os recursos exigidos e pela capacidade de envolvimento e comprometimento responsável e integrado das competências diretivas e técnicas das principais funções, que em instituições produtoras de informação técnica e estatística podem ser resumidas como: identificação de necessidades de informação; proposição de novos projetos e produtos; desenvolvimento de metodologia de pesquisa; captação e organização de dados e informações; análise; disseminação; comunicação interna e externa; adequação e inserção de tecnologia na otimização de processos; e desenvolvimento das competências institucionais e individuais.

\section{CONSIDERAÇÕES SOBRE O PLANEJAMENTO EM INSTITUIÇÕES PRODUTORAS DE INFORMAÇÃO}

O primeiro resultado da atividade de planejamento é selecionar objetivos e avaliar sua pertinência. Para isso, é necessário iniciar pelo estabelecimento de diretrizes para o desenvolvimento institucional, para a qualidade da coordenação e para a efetividade do sistema de informações em suas funções básicas: produção e disseminação da informação; e capacitação da produção. A demanda de produção tem origem em solicitações de informações por parte da comunidade social e do governo. Para a comunidade, é necessário que o sistema de produção seja pró-ativo e estabeleça uma agenda que acompanhe a demanda por explicação das principais questões e assegure o seu cumprimento. Com o governo é preciso negociar políticas, conhecer os planos e desenvolvimentos esperados que precisam de apoio de informações.

A atualidade do papel das instituições na geração, integração e disseminação de informações é referência para determinar diretrizes, em cada estágio da sua maturidade institucional. A atualidade se evidencia na relevância da informação produzida, na integração do sistema de informações, no conhecimento antecipado das necessidades do governo e usuários - resultantes de preocupações sociais, econômicas ou governamentais -, nos esforços de integração e coordenação com outras fontes produtoras de informação, na disponibilidade da informação para aqueles que têm sob sua responsabilidade a tomada de decisões, nas inovações metodológicas de investigação estatística 
e no uso adequado de padrões e instrumentos de trabalho. Esta avaliação tem como objetivo a indicação das fragilidades acumuladas, dos aspectos restritivos e críticos e das competências e oportunidades, subsidiando a formulação das diretrizes para o desenvolvimento e a maturidade institucional aqui entendida como: capacidade de investimento em produtos e pesquisas; desempenho da produção junto aos usuários; aproveitamento da experiência institucional; e capacidade de articular parcerias com usuários e fornecedores de informação.

A aplicabilidade, o uso e o custo da informação produzida e a natureza e a freqüência com que as necessidades dos usuários são atendidas definem a efetividade da produção de informações. Demandas mal enunciadas, falta de diretórios de bases de dados e documentação da informação disponível, resultados da comparação entre cronogramas e custos reais e previstos e inadequações funcionais ou estruturais têm impacto no custo da informação produzida. A falta de conhecimento sobre o programa de disseminação das informações, a indisponibilidade das bases de micro, macro e meta-dados, o acesso à informação e a falta de clareza nas diretrizes para a função de disseminação se refletem no uso da informação. Escassez de formulações de uso das informações para atender à lógica de decisão das políticas públicas, desequilíbrio na priorização e na atribuição de recursos aos projetos, falta de decisões sobre medidas e objetivos de integração e coordenação entre as informações produzidas e reações dos usuários à resposta de suas necessidades são alguns fatores que têm impacto na aplicabilidade da informação. É impossível enfrentar todos os desafios de uma só vez. Planejar é, antes de tudo, saber fazer escolhas viáveis.

Objetivos estratégicos bem definidos orientam a escolha das metas operacionais. Se os objetivos estratégicos são expressos por um conjunto de indicadores, os problemas da produção provavelmente estarão entre as causas críticas que conformam os indicadores insatisfatórios. Estas causas críticas, analisadas e detalhadas sobre o aspecto da experiência, dos recursos exigidos e da viabilidade, organizados e orçados por projetos, fundamentam o plano de trabalho. Na demanda por coordenação, têmse os objetivos da gestão: capacidade de prover e articular recursos de informação e conhecimento, recursos organizativos, políticos e financeiros em função do tempo, prioridades estratégicas e operacionais concretamente estabelecidas no plano de trabalho, detalhado em projetos. O plano de trabalho em forma de projetos exige capacitação, metodologia e sistemas de gestão.
Estabelecida a estratégia de desenvolvimento para as competências organizacionais, é necessário completá-las estabelecendo objetivos para as competências individuais e das equipes: desenvolvimento, remuneração, avaliação, processo de ascensão, dimensionamento e adequação do quadro de pessoal. Estas condições são difíceis de se garantir em se tratando de instituições públicas. Entretanto, tais restrições não devem inibir a criação de um processo responsável de avaliação de possibilidades e formas de resposta, que devem ser contempladas no plano.

\section{EXPERIÊNCIA DA FUNDAÇÃO SEADE}

No período de 1991 a 1994, a Fundação Seade desenvolveu ações de planejamento, partindo do problema "O usuário é pouco valorizado". A explicação deste problema, usando a metodologia PES - Planejamento Estratégico Situacional, desenvolvida por Carlos Matus, ${ }^{1}$ revelou seis fatores críticos, entendidos como causa da situação "O usuário é pouco valorizado". Estes novos problemas foram enunciados como:

- conhecimento pouco preciso do mercado que se quer atingir;

- inadequação dos mecanismos de disseminação das informações;

- inadequação dos métodos de tratamento de informações;

- não existe "data-fatal";

- informação não é considerada produto;

- não são claras as prioridades.

Este trabalho harmonizou de tal forma o entendimento sobre a necessidade de atuar dentro desses objetivos que suscitou novo impulso na comunidade Seade, uma nova etapa do seu desenvolvimento. Esta experiência positiva motivou a Fundação Seade a contratar o Prof. Carlos Matus para ministrar um curso de PES, de 9 a 20 de maio de 1994. Um corte no orçamento, em 1995, resultou numa quebra deste processo e conseqüente desmonte da equipe. Como legado, permaneceu uma cultura de pensar por problemas, de estar atento a todos os pontos de vista dos envolvidos, de analisar a governabilidade das situações, de levantar o conhecimento sobre as questões de forma participativa, subsidiando os responsáveis pelas decisões.

Em 2001, a Fundação Seade coordenou e desenvolveu o plano de trabalho "Ações para o Desenvolvimento Institucional". Este projeto elegeu como diretriz duas qualidades essenciais às instituições públicas que produzem informação socioeconômica: credibilidade social - garantir 
a relevância, a fidedignidade, a qualidade e a disponibilização atualizada das informações necessárias à caracterização da dinâmica socioeconômica de um Estado com a complexidade de São Paulo -; e aplicabilidade e uso das informações produzidas - desempenho da produção Seade junto aos governo, parceiros institucionais, órgãos similares de pesquisa e atores sociais envolvidos com o uso de informações.

O processo de trabalho se desenvolveu numa agenda de conversações orientada por um roteiro que fundamentou a dinâmica das reuniões e garantiu a identificação, o aprofundamento e a seleção das questões relevantes que se constituíram referência para analisar alguns aspectos do desenvolvimento da Fundação Seade. "Prioridades e preocupações" foram inicialmente identificadas e organizadas segundo temas: missão, indicadores de avaliação externa, modelo organizacional, receita própria, infraestrutura, indicadores de avaliação interna, desenvolvimento do corpo técnico e administrativo, convivência, seminários e eventos culturais. A cada âmbito de problemas foi aplicado um protocolo de questões em que se procurou identificar o nível - alto, médio e baixo - das dificuldades e da experiência da Fundação Seade. A necessidade de amadurecer um modelo de organização que pudesse compatibilizar a missão Seade e o atendimento de projetos sob demanda, desenvolver visões integradas entre os diversos grupos temáticos, divulgar a Fundação Seade e desenvolver plano de carreira foram questões classificadas como: dificuldade alta e experiência baixa. Por outro lado, verificou-se que as questões pré-produzir e disponibilizar resposta às demandas já conhecidas e aperfeiçoar o diálogo entre as decisões da direção e do corpo técnico, apesar de serem classificadas como baixa dificuldade e alta experiência, continuavam sendo problemas não resolvidos. À criação de condições para estudo, intercâmbio de conhecimento e atualidade foi atribuída dificuldade baixa e experiência baixa. A aplicação deste protocolo para conhecer a relação cognitiva do grupo diretivo com os problemas foi de grande valia para ajustar a consciência real sobre os desafios. As classificações nem sempre se revelaram válidas no momento de atuar, mas foram oportunas para construir uma nova compreensão sobre as dificuldades.

Os atores, que de alguma forma tinham governabilidade sobre as ações projetadas, também foram identificados: atores internos (diretores, governo, conselho curador, gerentes, técnicos, funcionários) e atores externos (usuários, fornecedores de informação - prefeituras, empresas, secretarias, ministérios, cartórios, fontes de informação -, instituições similares no país e no exterior e agências de fomento). Numa segunda etapa, as importâncias da direção foram apresentadas ao Fórum de Gerentes, que pôde, então, conhecer e contribuir com as ações propostas. A colaboração dos gerentes e assessorias reafirmou a necessidade de pensar o Seade futuro, fazer um esforço de antever a instituição nos próximos dois e quatro anos, avaliar os eixos estruturantes do conhecimento e das competências, desenvolver um novo papel dentro do governo, universidades e institutos de pesquisa.

O Plano Ações para o Desenvolvimento Institucional priorizou a gestão de projetos, o aperfeiçoamento do modelo de organização e a adequação da infra-estrutura:

- Ação 1 - Desenvolver a gestão por projetos;

- Ação 2 - Adequar a infra-estrutura:

2.1 - pessoas (ações de atualização em pesquisa social, políticas públicas, economia regional e construção de indicadores, capacitação avançada em análise multivariada e amostragem e capacitação básica em estatística para técnicos envolvidos com pesquisa e não estatísticos);

2.2 - ambiência (disponibilizar um espaço de convivência e adequação do mobiliário);

2.3 - processamento (treinamento básico e avançado e programa de desenvolvimento de informática: organização e tratamento de bases de dados, Internet, tecnologia, sistemas, hardware e software, comitê consultivo de Internet, de tecnologia da informação, de avaliação de softwares estatísticos e organização de bases de dados);

- Ação 3 - Aperfeiçoar um modelo de organização com o objetivo de melhorar a sinergia entre a missão Seade e o atendimento de projetos demandados;

- Ação 4 - Atuar na gestão de pessoal (concurso público, programa de estágio, programas de incentivo a demandas por capacitação técnica e gerencial);

- Ação 5 - Desenvolver a comunicação interna e externa (seminários, pesquisa interna de opinião, matérias na mídia e Internet, sala de imprensa na Internet, agenda de eventos comemorativos, palestras para públicos externos sobre a produção de informações, comunicação com o usuário, divulgação do publishop e do site do Seade).

Na seqüência, estabeleceu-se uma rede de facilitadores que se responsabilizaram por detalhar as ações e monitorar sua execução, subsidiando sistematicamente a di- 
reção colegiada com indicadores de resultados e avaliações do nível de dificuldade encontrado.

Para o propósito deste artigo, cabe destacar o desenvolvimento da gestão de projetos. A Fundação Seade concentrou esforços no sentido de desenvolver conhecimentos, habilidades e instrumentos, visando incentivar a coordenação de compromissos dentro de uma visão integrada, otimizar e acompanhar a alocação dos recursos, coordenar e integrar as funções técnicas e funções administrativas para o melhor desempenho dos projetos. A capacitação das gerências dentro de uma visão de conjunto da administração de projetos, do entendimento do papel do gerente de projetos, da compreensão das características individuais e seu impacto no desempenho das equipes de projetos também foi contemplada.

Entre agosto e dezembro de 2002, profissionais do Seade, sob a orientação de uma equipe de professores da FIA/USP, foram capacitados no modelo referencial de gestão de projetos proposto pelo guia $\mathrm{PMBoK}$ - Project Management Body of Knowledge - do PMI - Project Management Institute. Para consolidar este aprendizado e adequar sua utilização às especificidades dos projetos Seade, o Comitê Seade de Gestão de projetos, em reuniões coordenadas pela Fundação Instituto de Administração (FIA), desenvolveu, no período de março a abril de 2003, o Manual de Gestão de Projetos Seade, que define e detalha uma metodologia estruturada, buscando assegurar que os vários elementos do projeto sejam coordenados. $\mathrm{O}$ objetivo é oferecer um conjunto de diretrizes e procedimentos e identificar papéis (responsabilidades e autoridades) que possam servir de referência básica na condução das atividades da gestão de projetos.
O Manual de Gestão de Projetos Seade estabelece o entendimento comum do que é um projeto, caracteriza os tipos de projetos da Fundação Seade, estuda o ciclo de vida dos projetos (Quadro 1), avalia a complexidade dos projetos e estrutura uma metodologia identificando processos (Quadro 2), fluxos de trabalho e decisões, responsabilidades e desenvolvimento de funções para a organização de um sistema de informações que possa apoiar a gestão por projetos.

Neste trabalho, o estudo sobre os fatores críticos que têm impacto na complexidade dos projetos resultou nos seguintes critérios:

- origem da demanda: governamental, institucional, interna e externa;

- complexidade técnica: metodologia (continuidade, adaptação, inovação); execução (desenho amostral - pequeno, médio, grande -, estratégia operacional - continuidade, adaptação, inovação) e tecnologia (existente, adaptação, nova);

- recursos humanos: disponibilidade segundo o cronograma do projeto (disponível, não-disponível) e número de pessoas alocadas no projeto (pequeno, médio, alto, muito alto);

- áreas técnicas envolvidas: internas (uma gerência, mais de uma gerência) e externas (não existem, existem instituições externas envolvidas na execução do projeto);

- custos: baixo, médio, alto;

- duração: pequena, média, grande;

- dificuldade de obtenção de recursos materiais: pouca, média, alta (regras das instituições públicas).

QUADRO 1

Manual de Gestão de Projetos Seade: Ciclo de Vida dos Projetos

\begin{tabular}{|c|c|c|c|}
\hline \multicolumn{4}{|c|}{ Fases do Gerenciamento dos Projetos } \\
\hline \multirow{4}{*}{ Iniciação } & \multicolumn{2}{|c|}{$\begin{array}{c}\text { Fase Operacional } \\
\text { (comum a todos os tipos de projetos) }\end{array}$} & \multirow{4}{*}{ Encerramento } \\
\hline & \multirow{2}{*}{ Planejamento } & Execução & \\
\hline & & Controle & \\
\hline & \multicolumn{2}{|c|}{$\begin{array}{l}\text { - Desenvolvimento da metodologia da pesquisa (elaboração do instrumental de coleta, consistência de dados e qualidade) } \\
\text { - Coleta de dados, desenvolvimento do plano de análise e plano tabular } \\
\text { - Geração das bases de dados e processamento do plano tabular } \\
\text { - Análise dos resultados } \\
\text { - Elaboração dos produtos finais } \\
\text { - Disseminação das informações }\end{array}$} & \\
\hline
\end{tabular}

Fonte: Fundação Seade. 
QUADRO 2

Manual de Gestão de Projetos Seade: Fases e Processos

\begin{tabular}{|c|c|c|c|}
\hline 1. Iniciação & 2. Planejamento & $\begin{array}{l}\text { 3. Execução e } \\
\text { 4. Controle }\end{array}$ & 5. Encerramento \\
\hline 1.1 Analisar oportunidades & 2.1 Definir equipe de planejamento & 3.1 Detalhar o plano do projeto & 5.1 Encerrar projeto \\
\hline \multirow[t]{12}{*}{ 1.2 Autorizar o projeto } & 2.2 Detalhar o escopo do projeto & 3.2 Executar o plano operacional & 5.2 Finalizar a aceitação \\
\hline & 2.3 Definir recursos e aquisições externas & 3.3 Solicitar e acompanhar aquisições & 5.3 Documentar aprendizado \\
\hline & 2.4 Identificação de riscos & 3.4 Executar plano de comunicação & \\
\hline & 2.5 Desenvolver cronograma & & \\
\hline & 2.6 Estimar custos e preço & 4.1 Controle de desvios de desempenho & \\
\hline & 2.7 Validar plano do projeto & 4.2 Controle de alterações & \\
\hline & 2.8 Encaminhar decisão sobre o projeto & & \\
\hline & 2.9 Preparar e acompanhar solicitações & & \\
\hline & de financiamento & & \\
\hline & 2.10 Encaminhar decisão sobre o projeto & & \\
\hline & 2.11 Preparar e acompanhar proposta técnica & & \\
\hline & 2.12 Encaminhar decisão & & \\
\hline
\end{tabular}

Fonte: Fundação Seade.

O manual também descreve e detalha as responsabilidades de cada "papel", identificando, para cada processo, o tipo de atuação: se executa, gerencia, apóia, aprova ou acompanha. Convencionou-se definir "papéis" como um conjunto de atribuições de trabalho ou roteiros organizados de modo a garantir a execução dos procedimentos. Em sua maioria, os papéis adotados no manual independem da estrutura organizacional formal e são ocupados por profissionais do quadro, alocados temporariamente, de modo exclusivo ou não. Os papéis podem ser subdivididos em decisórios, operacionais e de suporte. Os decisórios são as atribuições de decisão sobre o projeto e implica, necessariamente, que tenha correspondência com as funções diretivas, ou com suas delegações formais. Os papéis operacionais são as atribuições operacionais diretas da gestão e da execução do projeto, que tendem a ser preenchidas por profissionais das áreas técnicas. Os papéis de suporte são atribuições de suporte e apoio administrativo à gestão e à execução do projeto, que tendem a ser preenchidas por profissionais das gerências e assessorias. O Sistema de Informações da Gestão de Projetos, ferramenta fundamental para o sucesso da gestão de projetos, também é descrito nas suas funcionalidades: deve suportar os aspectos do projeto desde o início até o encerramento; pode incluir tanto sistemas manuais como automatizados; deve ser integrado com os sistemas já existentes; e consolidar informações para a direção providenciando diversos níveis de informação.
Estão em fase de detalhamento as próximas ações: treinamento e teste da metodologia; aplicações-piloto para cada tipo de projeto; atualização da versão atual do manual de gestão de projetos a partir do aprendizado nas aplicações-piloto; adequação e expansão do atual sistema de informações para suportar as funcionalidades da metodologia; e implantação do escritório de projetos.

Este trabalho de planejamento contribuiu ainda para o significativo esforço de capacitação técnica, programas de incentivo a novas especializações e atualização da tecnologia da informação. Hoje, está em processo de implementação o espaço de convivência e a diretoria retomou a demanda "Aperfeiçoar o modelo de organização da Fundação Seade”.

\section{NOTA}

1. Economista, ministrou a cátedra de Política Econômica nos cursos de pós-graduação em Planejamento da Cepal e do Instituto Latino-Americano de Planificación Y Desarrollo (Ilpes) das Nações Unidas. Autor de vários livros sobre planejamento. Presidiu a Fundación Altadir, Caracas, Venezuela.

\section{REFERÊNCIAS BIBLIOGRÁFICAS}

CRUZ, A.C. de A. et al. Manual de gestão de projetos Seade. São Paulo: Seade, 2003. 124p.

DAMÁSIO, A. O mistério da consciência. São Paulo: Ed. Schwarcz Ltda., 2000. 474p. 
DAVENPORT, T.H.; PRUSAK, L. Conhecimento empresarial: como as organizações gerenciam o seu capital intelectual. Rio de Janeiro: Campus, 1998.

GEUS, A. de. A empresa viva: como as organizações podem aprender a prosperar e se perpetuar. Rio de Janeiro: Campus, 1998.

HANS-GEORG, G. Verdade e método. São Paulo: Vozes, 1997. 731p.

KAO, J.J. A arte e a disciplina da criatividade na empresa. Rio de Janeiro: Campus, 1997. 211p.

KRUGLIANSKAS, I.; TERRA, J.C.C. Gestão do conhecimento em pequenas e médias empresas - lições extraídas de casos reais. São Paulo: Negócio Editora, 2003.

MATUS, C. Planejamento estratégico situacional: guia de análises teórico. Venezuela: Fundação Altadir, 1994. 210p. I, 1993.

Politica, planejamento \& governo. Brasília: Ipea, tomo

. O plano como aposta. São Paulo em Perspectiva, São Paulo, Fundação Seade, v.5, n.4, p.22-42, out./dez. 1991.
OLIVEIRA, D. de P.R. Sistemas, organização \& métodos \& OM-uma abordagem gerencial. São Paulo: Atlas S.A., 2002.

PETERS, T. Rompendo as barreiras da administração: a necessária desorganização para enfrentar a nova realidade. São Paulo: Ed. Harbra Ltda., 1993.

PMBOK GUIDE. Conjunto de conhecimentos do gerenciamento de projetos. Pennsylvania: Project Management Institute, 2000.

SCHWARTZ, P. A arte da previsão: planejando o futuro em um mundo de incertezas. São Paulo: Página Aberta, 1995.

ZILHÃO, M.J.; CLODE, T. Qualidade em estatística. Portugal: Instituto Nacional de Estatística, 2003.

Maria Josefa Del Carmen Martinez Soto: Estatística, Assessora de Planejamento da Fundação Seade. 